\title{
Hydrogen peroxide promotes the expression of angiopoietin like 4 in RAW264.7 macrophages via MAPK pathways
}

\author{
NAN LIU ${ }^{1,2}$, CHANGXIA CUI $^{1}$, YUE SUN $^{2}$, FENG ZHANG $^{3}$, SHUYA WANG $^{1,2}$, GUOHAI SU $^{1}$ and XIAOJUN CAI ${ }^{1,2}$ \\ ${ }^{1}$ Department of Cardiovascular Medicine, Jinan Central Hospital Affiliated to Shandong University; \\ ${ }^{2}$ Department of Cardiology, Shandong University, Cheeloo College of Medicine, Jinan, Shandong 250013; \\ ${ }^{3}$ Department of Cardiology, Tengzhou Central People's Hospital, Tengzhou, Shandong 277500, P.R. China
}

Received October 12, 2016; Accepted March 23, 2017

DOI: $10.3892 / \mathrm{mmr} .2017 .7365$

\begin{abstract}
Previous studies including some vivo experiments and large scale clinical trials have indicated that angiopoietin like 4 (ANGPTL4) is involved in atherosclerosis. However, the specific mechanism underlying the process remains unresolved. Similarly, cumulative evidence indicated that hydrogen peroxide $\left(\mathrm{H}_{2} \mathrm{O}_{2}\right)$ is closely related to the occurrence and development of atherosclerosis. The current study investigated whether $\mathrm{H}_{2} \mathrm{O}_{2}$ treatment can affect ANGPTL4 release in macrophage cells cell viability assay, western blot analysis, ELISA and immunofluorescence. It was determined that treatment with 0.25 and $0.5 \mathrm{mM} \mathrm{H}_{2} \mathrm{O}_{2}$ resulted in a significant increase in ANGPTL4 protein expression in macrophage cells. Mitogen-activated protein kinase (MAPK) pathways were implicated in the secretion of ANGPTL4 regulated by $\mathrm{H}_{2} \mathrm{O}_{2}$, and specific inhibitors of MAPK1 (also known as ERK) and p38 MAPK significantly decreased $\mathrm{H}_{2} \mathrm{O}_{2}$ induced ANGPTL4 protein expression. Accordingly, it was demonstrated that ANGPTL4 expression was regulated by $\mathrm{H}_{2} \mathrm{O}_{2}$ via ERK and $\mathrm{p} 38$ MAPK, but not the MAPK8 (also known as JNK) pathway. In view of the effects of $\mathrm{H}_{2} \mathrm{O}_{2}$ and ANGPTL4 on atherosclerosis, the influence of $\mathrm{H}_{2} \mathrm{O}_{2}$ on ANGPTL4 provided new insight into the mechanism of atherosclerosis.
\end{abstract}

\section{Introduction}

Angiopoietin like 4 (ANGPTL4) was first identified as a novel protein with a similar structure to other angiopoietin-like proteins. Angiopoietin-like proteins have a structure composed of an N-terminal coil-coil structure and a C-terminal fibrinogen-like domain (1). ANGPTL4 is primarily expressed in the

Correspondence to: Professor Xiaojun Cai, Department of Cardiovascular Medicine, Jinan Central Hospital Affiliated to Shandong University, 105 Jiefang Road, Jinan, Shandong 250013, P.R. China

E-mail: 15066126206@163.com

Key words: angiopoietin like $4, \mathrm{H}_{2} \mathrm{O}_{2}$, mitogen-activated protein kinase pathways, macrophage, atherosclerosis liver, adipose tissues, heart, skeletal muscle, intestine, blood plasma, ovaries and the placenta in humans (2). ANGPTL4 is involved in many physiological and pathological conditions including lipid metabolism, glucose homoeostasis, inflammation, kidney disease, wound healing, cell differentiation, tumorigenesis, angiogenesis, vascular permeability and redox regulation (3). Peroxisome proliferator-activated receptors (PPARs) transcriptionally stimulate ANGPTL4 expression via the PPAR-response element and transforming growth factor $\beta$ (TGF- $\beta$ ), which transcriptionally stimulates ANGPTL4 expression via the TGF- $\beta$ responsive enhancer. Furthermore, PPARs and TGF- $\beta$ can synergistically or antagonistically regulate ANGPTL4 expression (4). Hypoxia also elevates the expression of ANGPTL4 by transcriptional regulation by hypoxia-inducible factor 1 (HIF-1) (5). PPARs and HIF-1 have a synergistic interaction in regulating ANGPTL4 transcription by changing the conformational proximity of corresponding response elements (6).

Reactive oxygen species (ROS) are a class of chemically reactive oxygen-containing compounds, including superoxide, hydroxyl radicals and hydrogen peroxide $\left(\mathrm{H}_{2} \mathrm{O}_{2}\right)$, which serve important roles in normal biochemical functions and abnormal pathological processes (7). The accumulation of ROS can cause protein dysfunction and DNA damage. ROS also function as chemical messengers to activate signaling pathways that are involved in cell proliferation, differentiation, and apoptosis (8). Of particular interest is $\mathrm{H}_{2} \mathrm{O}_{2}$, which is mainly produced in biological systems by the dismutation of the superoxide anion in a reaction carried out by the enzyme superoxide dismutase. $\mathrm{H}_{2} \mathrm{O}_{2}$ is not only thought to function as a cellular damaging agent that reacts toward lipids, proteins, and DNA, but also acts as a crucial mediator of intracellular signaling. As a crucial second messenger, $\mathrm{H}_{2} \mathrm{O}_{2}$ can activate a myriad of signaling pathways of which the best known are the mitogen-activated protein kinase (MAPK) pathways (9). The MAPKs are highly conserved serine/threonine protein kinases that function in various fundamental cellular processes, including proliferation, differentiation, motility, apoptosis and survival (10). Increasing the concentration of $\mathrm{H}_{2} \mathrm{O}_{2}$ promotes phosphorylation of apoptosis signal-regulating kinase 1 (ASK1). ASK1 is a MAPK that activates MAPK8 (commonly known as JNK) and p38 MAPK, but not MAPK1 (commonly known as ERK) (11). Besides, $\mathrm{H}_{2} \mathrm{O}_{2}$ may activate MAPKs 
pathways via other mechanisms such as the nuclear factor- $\kappa \mathrm{B}$ MAPK pathway $(12,13)$. Furthermore, a previous study demonstrated that increased p38 activity produced a positive feedback to enhance ROS generation by upregulating nicotinamide adenine dinucleotide phosphate-oxidase, $\mathrm{H}_{2} \mathrm{O}_{2}$ and $\mathrm{p} 38$ to develop a positive feedback loop (14). Accordingly, MAPKs act on respiratory burst oxidase homologs, a type of NADPH oxidase in plants, and thus accelerate ROS production (15).

ERK and JNK are both involved in the induction of ANGPTL 4 by para-methoxyamphetamine (PMA) in human airway smooth muscle cells, and a role for p38 in PMA-induced ANGPTL4 increase has been excluded (16). In addition, the ERK inhibitor, U0126, and the JNK inhibitor, SP600125, greatly inhibit the increase in ANGPTL4 expression (16). In the human glioblastoma cell line LN229, ANGPTL4 expression is significantly induced by epidermal growth factor receptor variant type III (EGFRIII). In this process, the MAPK pathway, especially ERK is activated with the transcription factor c-Myc, which regulates ANGPTL4 transcription (17).

Considering the importance of MAPK signaling pathways with regard to $\mathrm{H}_{2} \mathrm{O}_{2}$ and ANGPTL4, it was hypothesized that there may be a mutual effect of $\mathrm{H}_{2} \mathrm{O}_{2}$ on ANGPTL4. To the best of our knowledge, the potential role of $\mathrm{H}_{2} \mathrm{O}_{2}$ in the regulation of ANGPTL4 release has not been investigated previously. The present study was therefore undertaken to determine the effects of $\mathrm{H}_{2} \mathrm{O}_{2}$ treatment on ANGPTL4 release in macrophage cells.

\section{Materials and methods}

Materials. $\mathrm{H}_{2} \mathrm{O}_{2}$ (cat. no. 323381) was purchased from Sigma-Aldrich; Merck KGaA (Darmstadt, Germany) and diluted in PBS (Gibco; Thermo Fisher Scientific, Inc., Waltham, MA, USA). Fetal bovine serum (FBS; cat. no. F8240) was purchased from Hangzhou Four Seasons Green Engineering Materials Co., Ltd., (Hangzhou, China) and Dulbecco's modified Eagle's medium (DMEM; cat. no. C11995500BT) from Gibco; Thermo Fisher Scientific, Inc. Primary antibody against $\alpha$-tubulin (cat. no. 60031-1-ig) was purchased from Wuhan SanYing Biotechnology, Inc. (Wuhan, China). Primary antibody against ANGPTL4 (cat. no. 40-9800) was obtained from Invitrogen; Thermo Fisher Scientific, Inc. Primary antibodies against phosphorylated (p-)p38 MAPK (cat. no. 4511), p38 MAPK (cat. no. 8690), p-ERK1/2 (cat. no. 4370), ERK1/2 (cat. no. 4695), p-JNK (cat. no. 4668) and JNK (cat. no. 9252) were purchased from Cell Signaling Technology, Inc. (Danvers, MA, USA), as were U0126 (cat. no. 9903) and SB203580 (cat. no. 5633). SP600125 (cat. no. S5567) was purchased from Sigma-Aldrich; Merck KGaA. Goat anti-rabbit secondary antibody (cat. no. 2301) and rabbit anti-mouse secondary antibody (cat. no. ZB2305) were obtained from OriGene Technologies, Inc. (Beijing, China). The primary anti-ANGPTL4 antibody (cat. no. 251458) used for cell immunofluorescence was obtained from Abbiotec LLC (San Diego, CA, USA) and the goat anti rabbit fluorescent secondary antibody (cat. no. A-11034) was from Applied Biosystems; Thermo Fisher Scientific, Inc. Cell Counting Kit-8 (CCK-8) was obtained from BestBio (Shanghai, China) and the mouse ANGPTL4 ELISA kit (cat. no. KB18884) was purchased from Jiang Lai Bio-Technology (Shanghai, China).
Cell culture and treatment. Murine macrophage RAW264.7 cells were obtained from Shanghai Type Culture Collection (Shanghai, China). Cells were cultured in DMEM supplemented with $10 \% \mathrm{FBS}, 1 \%$ penicillin and streptomycin, and incubated at $37^{\circ} \mathrm{C}$ in $5 \% \mathrm{CO}_{2}$. For the experiments, the cells were stimulated for $24 \mathrm{~h}$ with $\mathrm{H}_{2} \mathrm{O}_{2}$ at various concentrations. The specific inhibitors U0126, SB203580 and SP600125 were dissolved in DMSO to appropriate concentrations and used at 20, 40 and $10 \mathrm{mM}$, respectively. For pretreatments, cells were incubated for 30 min with SP600125, 90 min with SB203580, or 90 min with $\mathrm{U} 0126$, prior to $\mathrm{H}_{2} \mathrm{O}_{2}$ treatment.

Cell viability assay. Cell viability was evaluated by CCK-8 assay. The cells were cultured at a density of $10^{5}$ cells/well on 96-well plates in $100 \mu \mathrm{l}$ culture medium as described above. Following $24 \mathrm{~h}$ of culturing, the cells were stimulated with or without $\mathrm{H}_{2} \mathrm{O}_{2}(0.25$ or $0.5 \mathrm{mM})$ for $24 \mathrm{~h}$. Then the cells of each microwell were incubated with $10 \mu \mathrm{l}$ CCK8 and $90 \mu \mathrm{l}$ culture medium for $2 \mathrm{~h}$ at $37^{\circ} \mathrm{C}$ and then the absorption values were measured at $450 \mathrm{~nm}$ using a microplate reader (Bio-Rad Laboratories, Inc., Hercules, CA, USA). Cell viability was expressed as a percentage of the control.

Western blot analysis. Following pretreatment and $\mathrm{H}_{2} \mathrm{O}_{2}$ treatment, cells and culture media were separated by centrifugation at $4^{\circ} \mathrm{C}$ for $20 \mathrm{~min}$ at $2,000 \mathrm{x} \mathrm{g}$. Total protein was extracted from cells for western blotting, while the culture medium was saved for ELISAs. Total protein was extracted using radioimmunoprecipitation assay buffer (Beyotime Institute of Biotechnology, Beijing, China), which contained 0.1 M phenylmethylsulfonyl fluoride. Following washing with PBS, grinding, lysis and centrifugation (at $4^{\circ} \mathrm{C}, 13,000 \mathrm{x} \mathrm{g}, 15 \mathrm{~min}$ ), the supernatant was collected. Then proteins (100 $\mu \mathrm{g}$ per lane) were separated by $10 \%$ SDS-PAGE and transferred to polyvinylidene difluoride membranes. Membranes were blocked by incubation for $90 \mathrm{~min}$ at room temperature in 5\% non-fat milk in TBS $+0.2 \%$ Tween-20 (TBST). Membranes were incubated at $4{ }^{\circ} \mathrm{C}$ overnight with the following specific primary antibodies: $\alpha$-tubulin $(1: 5,000)$, ANGPTL4 (1:1,000), p-p38 MAPK (1:1,000), p38 MAPK (1:1,000), p-ERK1/2 (1:1,000), ERK $(1: 1,000)$, p-JNK $(1: 1,000)$ and JNK $(1: 1,000)$. Membranes were then incubated with horseradish peroxidase-conjugated secondary antibodies $(1: 5,000)$ in $5 \%$ non-fat milk in TBST for $1 \mathrm{~h}$ at room temperature. Finally, bands were detected using chemiluminescence kit (EMD Millipore Billerica, MA, USA) and quantified with the FluorChem E system (ProteinSimple; Bio-Techne, Minneapolis, MN, USA).

Immunofluorescence. Cells $\left(\sim 1 \times 10^{5} / \mathrm{ml}\right)$ were cultured on cover slips and then treated with or without $\mathrm{H}_{2} \mathrm{O}_{2}$ for $24 \mathrm{~h}$. Cells were then fixed in $4 \%$ paraformaldehyde for $15 \mathrm{~min}$ prior to extraction with $0.5 \%$ Triton $\mathrm{X}-100$. Then, nonspecific antibodies were blocked by incubation with goat serum (Beijing Zhongshan Jinqiao Biotechnology Co., Ltd., Beijing, China) for $30 \mathrm{~min}$ at $37^{\circ} \mathrm{C}$ and then incubated with anti-ANGPTL4 antibody at $4^{\circ} \mathrm{C}$ overnight, followed by incubation with AlexaFluor-488 goat anti-rabbit IgG (cat. no. A-11034; Thermo Fisher Scientific, Inc.) for $45 \mathrm{~min}$ at $37^{\circ} \mathrm{C}$. Slides were then incubated with 4',6-diamidino-2-phenylindole to counterstain and fluorescent signals were 
detected using a light microscope; $>3$ fields of view were examined in $\sim 9$ slides.

ELISA. The culture medium in 6-well plates was collected as described above, and the quantity of ANGPTL4 protein in the culture medium was determined by ELISA. The absorbance at $450 \mathrm{~nm}$ was detected using a microplate reader and ANGPTL4 levels were calculated according to a standard curve.

Statistical analysis. Statistical analysis was performed using GraphPad Prism version 5.01 (GraphPad Software, Inc., La Jolla, CA, USA) and all experimental data are presented as the mean \pm standard deviation of at least three independent experiments. Comparisons between two groups were performed using two-tailed Student's t-tests. Multiple comparisons were performed by one way analysis of variance followed by Bonferroni's test. $\mathrm{P}<0.05$ was considered to indicate a statistically significant difference.

\section{Results}

$\mathrm{H}_{2} \mathrm{O}_{2}$ induces ANGPTL4 release in $\mathrm{RAW} 264.7$ macrophage cells. To study the effect of $\mathrm{H}_{2} \mathrm{O}_{2}$ on ANGPTL4 protein expression, $0,0.125,0.25,0.375$ and $0.5 \mathrm{mM} \mathrm{H}_{2} \mathrm{O}_{2}$ was added to macrophage cells. The lowest concentration, $0.125 \mathrm{mM}$, increased ANGPTL4 protein levels slightly compared with control, but was not statistically significant (data not shown). As demonstrated by immunofluorescence, incubation of cells with 0.25 and $0.5 \mathrm{mM} \mathrm{H}_{2} \mathrm{O}_{2}$ for $24 \mathrm{~h}$ resulted in significantly more ANGPTL4 in the cytoplasm and the nucleus compared with control $(\mathrm{P}<0.001$; Fig. 1A). Significant upregulation of ANGPTL4 protein expression compared with the control was also observed by western blotting (Fig. 1B). In addition, significantly more ANGPTL4 was secreted into the medium in cells treated with 0.25 and $0.5 \mathrm{mM} \mathrm{H}_{2} \mathrm{O}_{2}$ compared with control, as detected by ELISA $(\mathrm{P}<0.05$; Fig. 1C).

Regulation of ANGPTL4 by $\mathrm{H}_{2} \mathrm{O}_{2}$ is mediated by MAPK pathways. To gain insight into the underlying mechanism of $\mathrm{H}_{2} \mathrm{O}_{2}$-induced ANGPTL4 release, the roles of MAPK signaling pathways were investigated. The level of ERK1/2 (Fig. 2A), p38 MAPK (Fig. 2B) and JNK (Fig. 2C) phosphorylation in cells stimulated with 0.25 and $0.5 \mathrm{mM} \mathrm{H}_{2} \mathrm{O}_{2}$ was significantly increased compared with control. It was therefore concluded that $\mathrm{H}_{2} \mathrm{O}_{2}$ effectively induced phosphorylation of ERK1/2, p38 MAPK and JNK proteins in the macrophage cells; however, this conclusion is insufficient to determine that $\mathrm{H}_{2} \mathrm{O}_{2}$-induced ANGPTL4 expression is dependent on MAPK pathway activation.

U0126 and SB203580 inhibit $\mathrm{H}_{2} \mathrm{O}_{2}$-induced ANGPTL4 release in RAW264.7 macrophage cells. To explore this issue further, the effects of specific inhibitors of p38 MAPK (SB203580), JNK (SP600125) and ERK1/2 (U0126) on $\mathrm{H}_{2} \mathrm{O}_{2}$-induced ANGPTL4 expression were investigated. As illustrated in Fig. 3A, compared with the uninhibited samples, preincubation of the cells with $20 \mathrm{mM}$ UO126 for $90 \mathrm{~min}$ to block ERK1/2 activation significantly inhibited overexpression of ANGPTL4 protein induced by $\mathrm{H}_{2} \mathrm{O}_{2}(\mathrm{P}<0.01)$. Similarly, preincubation of cells with $40 \mathrm{mM}$ SB203580 for 90 min to block p38 MAPK
A
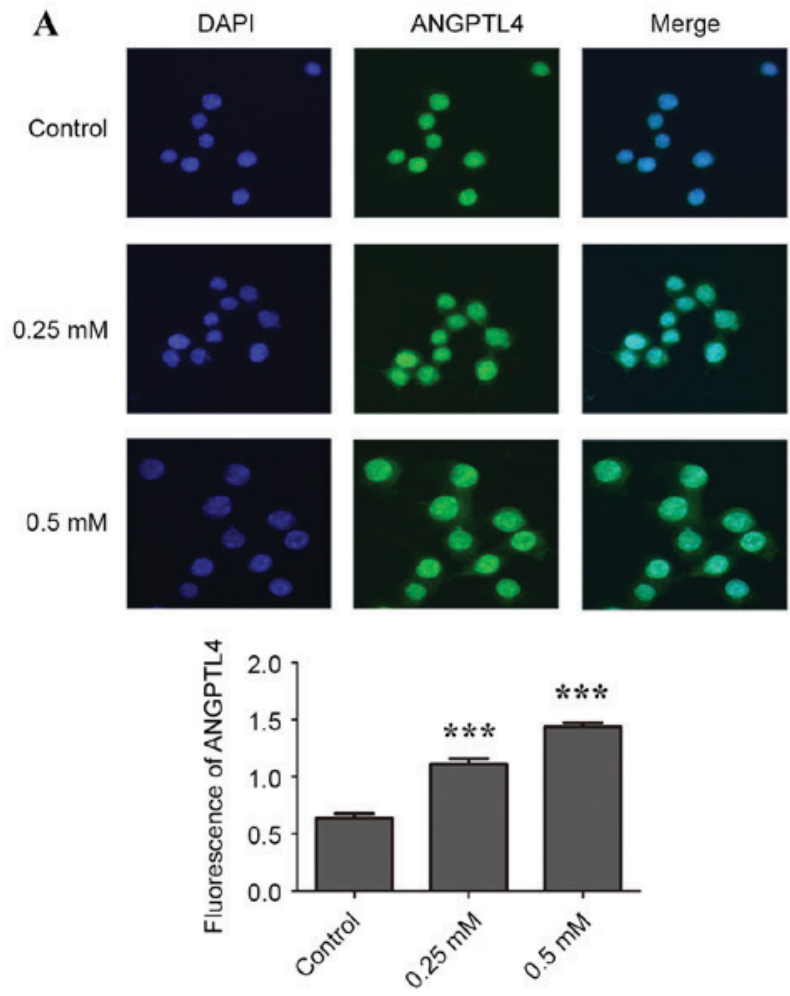

B

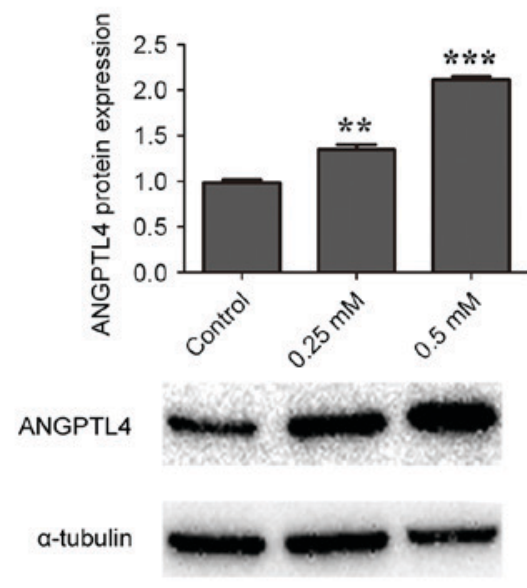

C

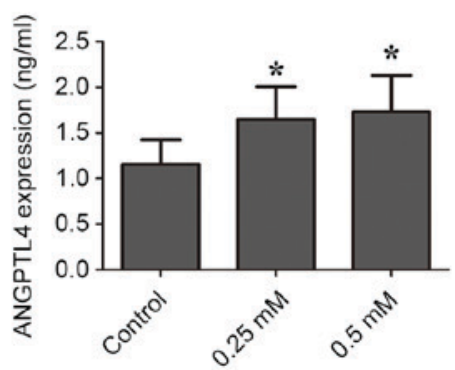

Figure 1. Effect of $\mathrm{H}_{2} \mathrm{O}_{2}$ on ANGPTL4 protein expression in RAW264.7 macrophage cells. (A) Cells were stimulated with 0 (control), 0.25 or $0.5 \mathrm{mM} \mathrm{H}_{2} \mathrm{O}_{2}$ for $24 \mathrm{~h}$, then ANGPTL4 protein expression in the cytoplasm and nucleus was determined by immunofluorescence. Cells were stimulated with 0 (control), 0.25 or $0.5 \mathrm{mM} \mathrm{H}_{2} \mathrm{O}_{2}$ for $24 \mathrm{~h}$, then ANGPTL4 protein expression in (B) cell lysates was determined by western blotting, with $\alpha$-tubulin as a loading control, and (C) ANGPTL4 protein expression in the culture medium was examined by ELISA. ${ }^{*} \mathrm{P}<0.05,{ }^{* *} \mathrm{P}<0.01$ and ${ }^{* * *} \mathrm{P}<0.001$ vs. control. ANGPTL4, angiopoietin like 4.

pathway activation inhibited overexpression of ANGPTL4 protein induced by $\mathrm{H}_{2} \mathrm{O}_{2}$ compared with uninhibited samples 

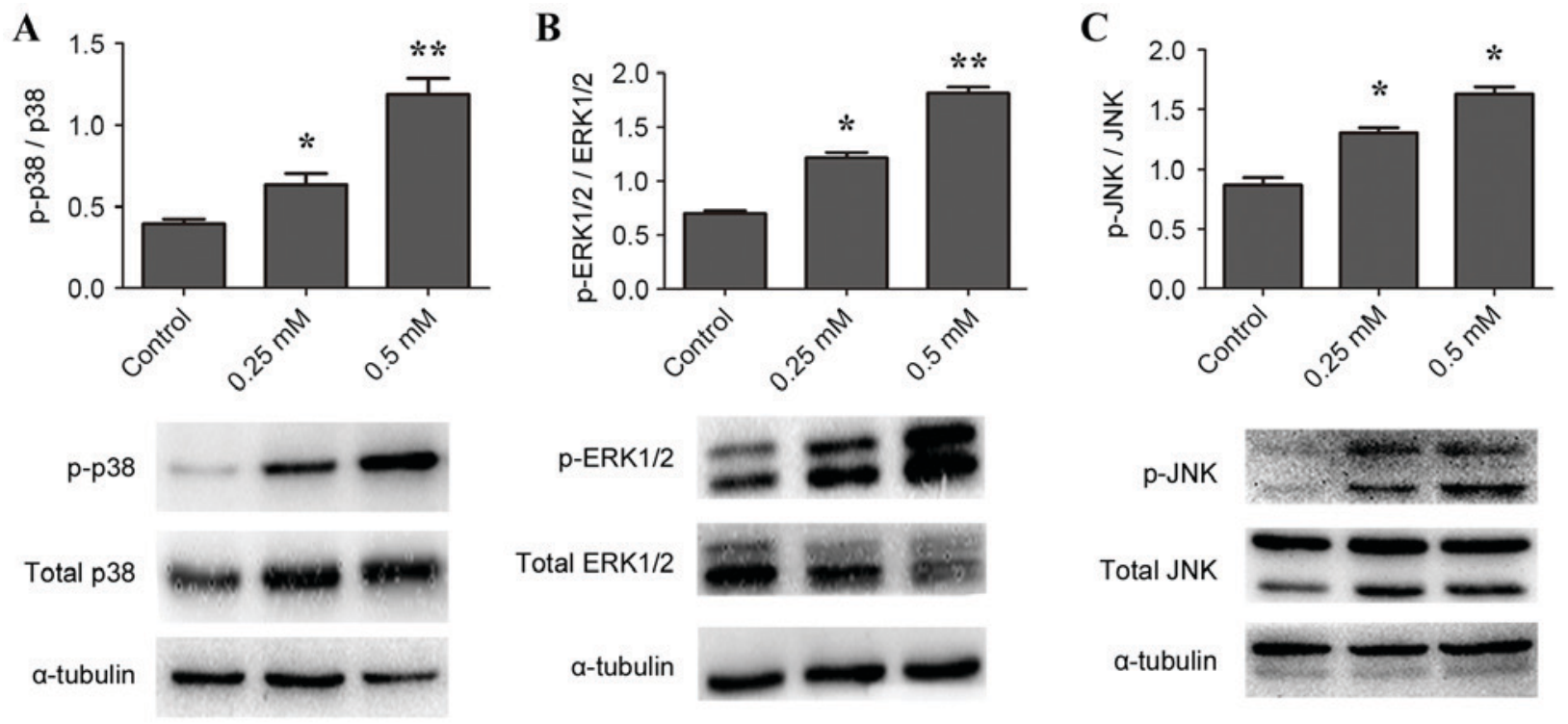

Figure 2. $\mathrm{H}_{2} \mathrm{O}_{2}$ activates ERK1/2, p38 MAPK and JNK protein phosphorylation expression in RAW264.7 macrophages. Cells were stimulated with 0 (control), 0.25 or $0.5 \mathrm{mM} \mathrm{H}_{2} \mathrm{O}_{2}$ for $24 \mathrm{~h}$, then protein expression in cell lysates was measured by western blotting. Cell lysates were probed for (A) p- and total ERK1/2, (B) p- and total p38 MAPK and (C) p- and total JNK, with $\alpha$-tubulin as loading control. ${ }^{*} \mathrm{P}<0.05,{ }^{* *} \mathrm{P}<0.01$ and ${ }^{* * * *} \mathrm{P}<0.001$ vs. control. ERK1/2, MAPK1; MAPK, mitogen-activated protein kinase; JNK, MAPK8; p-, phosphorylated.

( $\mathrm{P}<0.05$; Fig. 3B). However, compared with uninhibited samples, $\mathrm{H}_{2} \mathrm{O}_{2}$-induced ANGPTL4 protein levels were not affected in cells preincubated with $10 \mathrm{mM}$ SP600125 for 30 min to block JNK pathway activation (Fig. 3C). Due to the toxicity to the macrophage cells, it was not possible to increase the concentration of SP600125 further. Together these results indicated that inhibition of $\mathrm{p} 38 \mathrm{MAPK}$ and ERK1/2, but not JNK, attenuated $\mathrm{H}_{2} \mathrm{O}_{2}$-induced ANGPTL4 release in macrophage cells.

\section{Discussion}

In the present study, ANGPTL4 was identified as a protein that was upregulated in Raw264.7 macrophages exposed to high concentrations of exogenous $\mathrm{H}_{2} \mathrm{O}_{2}$. Macrophages are immune cells that take part in immune response associated disease, including atherosclerosis. Atherosclerosis primarily refers to a maladaptive immune response caused by the accumulation of cholesterol-laden macrophages in the artery wall $(18,19)$. Macrophages serve a key role via transition to foam cells that trigger the formation of an atherosclerotic lesion $(20,21)$. Furthermore, macrophage cell autophagy participates in atherosclerosis by exerting a protective influence (22). Macrophage cells secrete various kinds of pro-inflammatory cytokines, which form an indispensable part of the inflammation reaction in the genesis of atherosclerosis $(23,24)$., ANGPTL4 is highly expressed in macrophages. A previous study has indicated that ANGPTL4 decreases the uptake of oxidized low-density lipoprotein (ox-LDL) in macrophage cells and consequently suppresses foam cell formation which prevents the pathological development of atherosclerosis (25). By contrast, $\mathrm{H}_{2} \mathrm{O}_{2}$ has been demonstrated to promote the oxidative modification of LDL into ox-LDL and accelerate foam cell formation (26). Therefore, ANGPTL4 and $\mathrm{H}_{2} \mathrm{O}_{2}$ take opposite roles in the formation of foam cells. The present study linked ANGPTL4 and $\mathrm{H}_{2} \mathrm{O}_{2}$ via MAPK pathways. p38,
ERK and JNK are all activated by high concentrations of $\mathrm{H}_{2} \mathrm{O}_{2}$ in macrophages. However, only the ERK inhibitor U0126 and the p38 inhibitor SB203580 were demonstrated to suppress ANGPTL4 expression induced by $\mathrm{H}_{2} \mathrm{O}_{2}$. Although the JNK pathway was activated, the special inhibitor SP600125 did not significantly decrease $\mathrm{H}_{2} \mathrm{O}_{2}$-induced ANGPTL4 expression. In different cell types, $\mathrm{H}_{2} \mathrm{O}_{2}$ stimulates different subgroups of MAPKs and the mechanism is not well understood (27). ANGPTL4 interacts with integrins to stimulate NADPH oxidase-dependent production of ROS, particularly $\mathrm{O}_{2}$. A high ratio of $\mathrm{O}_{2}: \mathrm{H}_{2} \mathrm{O}_{2}$ activates the ERK pathways (28). Interestingly, the C-terminal of ANGPTL4 can inhibit the phosphorylation of ERK induced by b-FGF in turn (29).

ANGPTL4 is a lipid metabolism associated factor and abundant evidence has demonstrated that the hypertriglyceridemic effect of ANGPTL4 is mainly attributable to inhibition of lipoprotein lipase (LPL), the enzyme that hydrolyses triglycerides $(30,31)$. To date, the role of ANGPTL4 in atherosclerosis remains controversial. For the past few decades, the emphasis of research of ANGPTL4 on atherosclerosis has been concentrated on the regulation of lipid metabolism and it is still unknown whether ANGPTL4 directly affects the genesis and development of atherosclerosis. Some studies suggest that ANGPTL4 serves a protective role in atherosclerosis, and the mechanism is independent of the influence of ANGPTL4 on triglyceride levels. Indeed, one study demonstrated that gene knockout of ANGPTL4 is sufficient to protect against the development and progression of atherosclerosis by suppressing formation of foam cells and thereby reducing the atherosclerotic lesion size (32). In consideration of the diverse physiological functions of ANGPTL4, intensive experiments are required to resolve these discrepancies.

Besides promoting foam cell formation, $\mathrm{H}_{2} \mathrm{O}_{2}$ has critical roles in the pathogenesis of atherosclerosis by regulating the migration of smooth muscle cells, monocyte infiltration and apoptosis of vascular cells during advanced atherosclerotic 
A
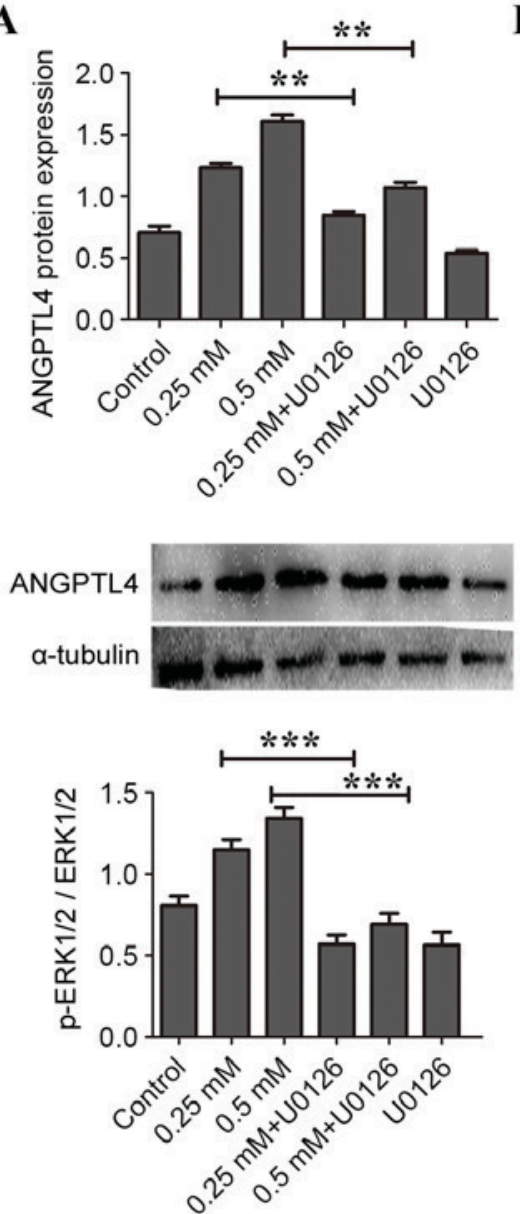

p-ERK1/2

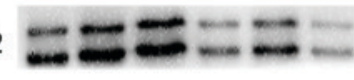

Total ERK1/2
B
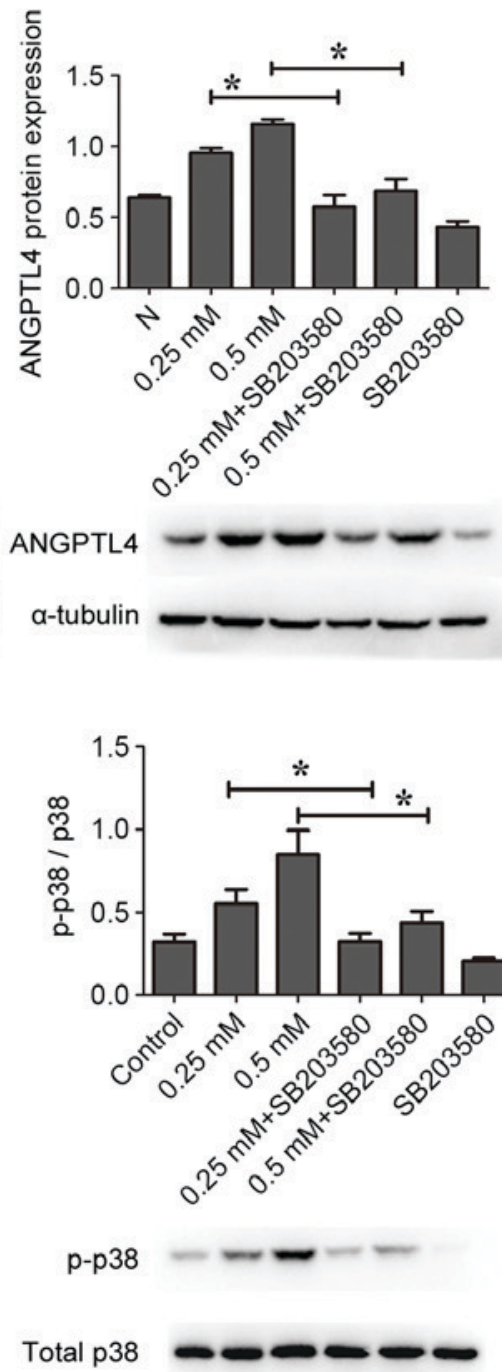

C
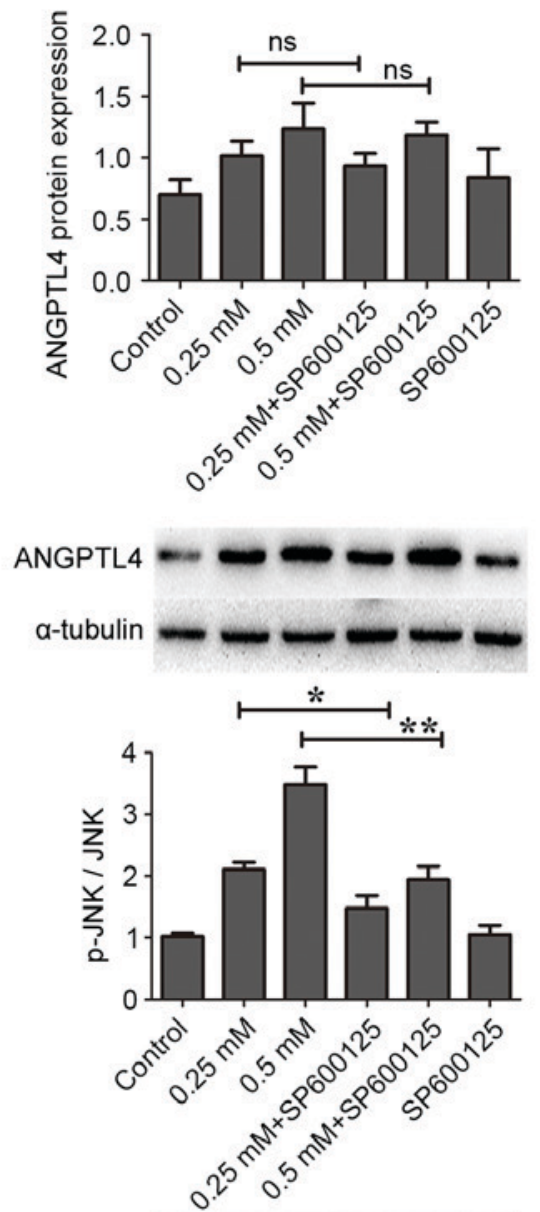

p-JNK

Trosulus

Figure 3. Effects of MAPK inhibitors on $\mathrm{H}_{2} \mathrm{O}_{2}$-induced ANGPTL4 release in RAW264.7 macrophage cells. Cells were pretreated with specific inhibitors for ERK1/2 (20 mM U0126), p38 MAPK (40 mM SB203580) or JNK (10 mM SP600125), followed by stimulation with 0, 0.25 or $0.5 \mathrm{mM} \mathrm{H}_{2} \mathrm{O}_{2}$ for 24 h. Protein expression levels were then determined by western blotting, with $\alpha$-tubulin as loading control. (A) ANGPTL4, p-ERK1/2 and total ERK1/2. (B) ANGPTL4, p-p38 MAPK and total p38 MAPK. (C) ANGPTL4, p-JNK and total JNK. ${ }^{*} \mathrm{P}<0.05,{ }^{* * *} \mathrm{P}<0.01$ and ${ }^{* * * *} \mathrm{P}<0.001$, with comparisons indicated by brackets. MAPK, mitogen-activated protein kinase; ANGPTL4, angiopoietin like 4; ERK1/2, MAPK1; JNK, MAPK8; p-, phosphorylated; Control, $0 \mathrm{mM} \mathrm{H}_{2} \mathrm{O}_{2}$ and no inhibitor; ns, not significant.

process (33-35). $\mathrm{H}_{2} \mathrm{O}_{2}$ has also been reported as inducer of autophagy which is involved in lipid homeostasis and dyslipidemias associated with atherosclerosis. During the development of atherosclerosis, $\mathrm{H}_{2} \mathrm{O}_{2}$ may inhibit smooth muscle cell migration by mediating the downregulation of myosin phosphatase target subunit 1 (36,37). Numerous studies have revealed that oxidative stress caused by $\mathrm{H}_{2} \mathrm{O}_{2}$ is a major factor contributing to the damage of endothelial cells; the resulting endothelial injury is an important pathological process of atherosclerosis (38). In addition, $\mathrm{H}_{2} \mathrm{O}_{2}$ is a crucial component of the redox signaling cascade which is involved in smooth muscle cell proliferation and migration in atherosclerosis (39). Additionally, the autophagy caused by $\mathrm{H}_{2} \mathrm{O}_{2}$ also contributes to atherosclerosis (40).

The findings of the present study demonstrate that $\mathrm{H}_{2} \mathrm{O}_{2}$ treatment of macrophage cells results in significantly increased ANGPTL4 expression and that the p38 MAPK and ERK1/2 signaling pathways are involved in the process. However, further studies are required to explain the exact effect of $\mathrm{H}_{2} \mathrm{O}_{2}$ on ANGPTL4 expression in atherosclerosis. Whether $\mathrm{H}_{2} \mathrm{O}_{2}$ acts as a trigger to activate other inflammatory factors that consequently promote ANGPTL4 expression is unknown. In addition, the inhibitors of p38 MAPK and ERK1/2 have not blocked $\mathrm{H}_{2} \mathrm{O}_{2}$ induced ANGPTL4 protein release completely, and whether other signaling pathways such as the PPARs pathways are implicated in this process requires further research. The present study reveals the communication between $\mathrm{H}_{2} \mathrm{O}_{2}$ and ANGPTL4 for the first time, and their interaction may produce an effect on atherosclerosis.

\section{Acknowledgements}

The authors thank the staff and participants for their contribution. The present study was supported by a grant from the National Science Foundation of Shandong Province (grant no. ZR2013HM003). 


\section{References}

1. Kim I, Kim HG, Kim H, Kim HH, Park SK, Uhm CS, Lee ZH and Koh GY: Hepatic expression, synthesis and secretion of a novel fibrinogen/angiopoietin-related protein that prevents endothelial-cell apoptosis. Biochem J 346: 603-610, 2000.

2. Mandard S, Zandbergen F, van Straten E, Wahli W, Kuipers F, Müller M and Kersten S: The fasting-induced adipose factor/angiopoietin-like protein 4 is physically associated with lipoproteins and governs plasma lipid levels and adiposity. J Biol Chem 281: 934-944, 2006.

3. Zhu P, Goh YY, Chin HF, Kersten S and Tan NS: Angiopoietinlike 4: A decade of research. Biosci Rep 32: 211-219, 2012.

4. Stockert J, Adhikary T, Kaddatz K, Finkernagel F, Meissner W, Müller-Brüsselbach S and Müller R: Reverse crosstalk of TGF $\beta$ and PPAR $\beta / \delta$ signaling identified by transcriptional profiling. Nucleic Acids Res 39: 119-131, 2011.

5. Drager LF, Yao Q, Hernandez KL, Shin MK, Bevans-Fonti S, Gay J, Sussan TE, Jun JC, Myers AC, Olivecrona G, et al: Chronic intermittent hypoxia induces atherosclerosis via activation of adipose angiopoietin-like 4. Am J Respir Crit Care Med 188: 240-248, 2013.

6. Inoue T, Kohro T, Tanaka T, Kanki Y, Li G, Poh HM, Mimura I, Kobayashi M, Taguchi A, Maejima T, et al: Cross-enhancement of ANGPTL4 transcription by HIF1 alpha and PPAR beta/delta is the result of the conformational proximity of two response elements. Genome Biol 15: R63, 2014.

7. Reczek CR and Chandel NS: ROS-dependent signal transduction. Curr Opin Cell Biol 33: 8-13, 2015.

8. Zhang J, Wang X, Vikash V, Ye Q, Wu D, Liu Y and Dong W: ROS and ROS-mediated cellular signaling. Oxid Med Cell Longev 2016: 4350965, 2016.

9. Marinho HS, Real C, Cyrne L, Soares H and Antunes F: Hydrogen peroxide sensing, signaling and regulation of transcription factors. Redox Biol 2: 535-562, 2014.

10. Lee Y, Kim YJ, Kim MH and Kwak JM: MAPK cascades in guard cell signal transduction. Front Plant Sci 7: 80, 2016.

11. Forman HJ: Use and abuse of exogenous H202 in studies of signal transduction. Free Radic Biol Med 42: 926-932, 2007.

12. Zikaki K, Aggeli IK, Gaitanaki C and Beis I: Curcumin induces the apoptotic intrinsic pathway via upregulation of reactive oxygen species and $\mathrm{JNKs}$ in $\mathrm{H} 9 \mathrm{c} 2$ cardiac myoblasts. Apoptosis 19: 958-974, 2014.

13. Vilema-Enríquez G, Arroyo A, Grijalva M, Amador-Zafra RI and Camacho J: Molecular and cellular effects of hydrogen peroxide on human lung cancer cells: Potential therapeutic implications. Oxid Med Cell Longev 2016: 1908164, 2016.

14. Zhang Q, Deng Y, Lai W, Guan X, Sun X, Han Q, Wang F, Pan X, Ji Y, Luo H, et al: Maternal inflammation activated ROS-p38 MAPK predisposes offspring to heart damages caused by isoproterenol via augmenting ROS generation. Sci Rep 6: 30146, 2016.

15. Jalmi SK and Sinha AK: ROS mediated MAPK signaling in abiotic and biotic stress-striking similarities and differences. Front Plant Sci 6: 769, 2015.

16. Stapleton CM, Joo JH, Kim YS, Liao G, Panettieri RA Jr and Jetten AM: Induction of ANGPTL4 expression in human airway smooth muscle cells by PMA through activation of PKC and MAPK pathways. Exp Cell Res 316: 507-516, 2010.

17. Katanasaka Y, Kodera Y, Kitamura Y, Morimoto T, Tamura T and Koizumi F: Epidermal growth factor receptor variant type III markedly accelerates angiogenesis and tumor growth via inducing c-myc mediated angiopoietin-like 4 expression in malignant glioma. Mol Cancer 12: 31, 2013.

18. Moore KJ, Sheedy FJ and Fisher EA: Macrophages in atherosclerosis: A dynamic balance. Nat Rev Immunol 13: 709-721, 2013.

19. Shirai T, Hilhorst M, Harrison DG, Goronzy JJ and Weyand CM: Macrophages in vascular inflammation-from atherosclerosis to vasculitis. Autoimmunity 48: 139-151, 2015.

20. Galkina E and Ley K: Immune and inflammatory mechanisms of atherosclerosis (*). Annu Rev Immunol 27: 165-197, 2009.

21. Patel KM, Strong A, Tohyama J, Jin X, Morales CR, Billheimer J, Millar J, Kruth H and Rader DJ: Macrophage sortilin promotes LDL uptake, foam cell formation, and atherosclerosis. Circ Res 116 789-796, 2015.
22. Liao X, Sluimer JC, Wang Y, Subramanian M, Brown K, Pattison JS, Robbins J, Martinez J and Tabas I: Macrophage autophagy plays a protective role in advanced atherosclerosis. Cell Metab 15: 545-553, 2012.

23. Briot A, Civelek M, Seki A, Hoi K, Mack JJ, Lee SD, Kim J, Hong C, Yu J, Fishbein GA, et al: Endothelial NOTCH1 is suppressed by circulating lipids and antagonizes inflammation during atherosclerosis. J Exp Med 212: 2147-2163, 2015.

24. Youn SW and Park KK: Small-nucleic-acid-based therapeutic strategy targeting the transcription factors regulating the vascular inflammation, remodeling and fibrosis in atherosclerosis. Int J Mol Sci 16: 11804-11833, 2015.

25. Georgiadi A, Wang Y, Stienstra R, Tjeerdema N, Janssen A, Stalenhoef A, van der Vliet JA, de Roos A, Tamsma JT, Smit JW, et al: Overexpression of angiopoietin-like protein 4 protects against atherosclerosis development. Arterioscler Thromb Vasc Biol 33: 1529-1537, 2013.

26. Tavakoli S and Asmis R: Reactive oxygen species and thiol redox signaling in the macrophage biology of atherosclerosis. Antioxid Redox Signal 17: 1785-1795, 2012.

27. Sies $\mathrm{H}$ : Role of metabolic $\mathrm{H} 2 \mathrm{O} 2$ generation: Redox signaling and oxidative stress. J Biol Chem 289: 8735-8741, 2014.

28. Zhu P, Tan MJ, Huang RL, Tan CK, Chong HC, Pal M, Lam CR, Boukamp P, Pan JY, Tan SH, et al: Angiopoietin-like 4 protein elevates the prosurvival intracellular $\mathrm{O} 2(-): \mathrm{H} 2 \mathrm{O} 2$ ratio and confers anoikis resistance to tumors. Cancer Cell 19: 401-415, 2011.

29. Yang YH, Wang Y, Lam KS, Yau MH, Cheng KK, Zhang J, Zhu W, Wu D and Xu A: Suppression of the Raf/MEK/ERK signaling cascade and inhibition of angiogenesis by the carboxyl terminus of angiopoietin-like protein 4 . Arterioscler Thromb Vasc Biol 28: 835-840, 2008.

30. Yau MH, Wang Y, Lam KS, Zhang J, Wu D and Xu A: A highly conserved motif within the $\mathrm{NH} 2$-terminal coiled-coil domain of angiopoietin-like protein 4 confers its inhibitory effects on lipoprotein lipase by disrupting the enzyme dimerization. J Biol Chem 284: 11942-11952, 2009.

31. Sukonina V, Lookene A, Olivecrona $\mathrm{T}$ and Olivecrona G: Angiopoietin-like protein 4 converts lipoprotein lipase to inactive monomers and modulates lipase activity in adipose tissue. Proc Natl Acad Sci USA 103: 17450-17455, 2006.

32. Adachi H, Fujiwara Y, Kondo T, Nishikawa T, Ogawa R, Matsumura T, Ishii N, Nagai R, Miyata K, Tabata M, et al: Angptl 4 deficiency improves lipid metabolism, suppresses foam cell formation and protects against atherosclerosis. Biochem Biophys Res Commun 379: 806-811, 2009.

33. Tsai MH and Jiang MJ: Reactive oxygen species are involved in regulating alpha1-adrenoceptor-activated vascular smooth muscle contraction. J Biomed Sci 17: 67, 2010.

34. Lassègue B, San Martín A and Griendling KK: Biochemistry, physiology, and pathophysiology of NADPH oxidases in the cardiovascular system. Circ Res 110: 1364-1390, 2012.

35. Konior A, Schramm A, Czesnikiewicz-Guzik M and Guzik TJ: NADPH oxidases in vascular pathology. Antioxid Redox Signal 20: 2794-2814, 2014

36. Cheng JC, Cheng HP, Tsai IC and Jiang MJ: ROS-mediated downregulation of MYPT1 in smooth muscle cells: A potential mechanism for the aberrant contractility in atherosclerosis. Lab Invest 93: 422-433, 2013.

37. Perrotta I and Aquila S: The role of oxidative stress and autophagy in atherosclerosis. Oxid Med Cell Longev 2015: 130315, 2015.

38. Griendling KK and FitzGerald GA: Oxidative stress and cardiovascular injury: Part II: Animal and human studies. Circulation 108: 2034-2040, 2003.

39. Moon SK, Thompson LJ, Madamanchi N, Ballinger S, Papaconstantinou J, Horaist C, Runge MS and Patterson C: Aging, oxidative responses, and proliferative capacity in cultured mouse aortic smooth muscle cells. Am J Physiol Heart Circ Physiol 280: H2779-H2788, 2001.

40. Li X, Xu M, Pitzer AL, Xia M, Boini KM, Li PL and Zhang Y: Control of autophagy maturation by acid sphingomyelinase in mouse coronary arterial smooth muscle cells: protective role in atherosclerosis. J Mol Med (Berl) 92: 473-485, 2014. 